\title{
Governance Shifts in Higher Education: a cross-national comparison
}

\author{
LUCIANA LAZZERETTI \\ University of Florence, Italy \\ ERNESTO TAVOLETTI \\ University of Macerata, Italy
}

\begin{abstract}
The article aims to interpret and compare recent governance shifts in higher education across several countries, both at the central government level and at the institutional or 'corporate' level. In order to do that it reviews the most significant literature about alternative theoretical models of governance in higher education and uses these models to interpret changing governance across several nations. It suggests the existence of a general tendency towards a 'new managerialism' governance model in Western Europe. In order to explain this tendency special attention is paid to countries in the forefront of governance innovation. The traditional continental European model is a term of comparison.
\end{abstract}

\section{Introduction}

European universities are going through a period of deep change, that is quickly and completely changing their role in society and in national, regional and local economic development. It is well known that these changes strongly involve university governance. However, universities are so linked to their countries that the examination of their governance structures cannot leave aside the governance structures of national higher education systems. Apart from particular characteristics, in fact, throughout Europe, universities are steered and coordinated by central states, directly or through the national university system. That is why we can say that university governance refers both to the single institution and to the national higher education system.

This phenomenon suggests two main research questions:

1. why and how university governance models are changing;

2. which new governance models are becoming apparent.

These questions seem to be particularly important in the debate regarding the reform of national university systems because they try to analyse typical models and tendencies in Europe and try to interpret this reform effort in a more general landscape. In many debates, you can notice, in fact, a strong path dependence on development of national regulations and little attention to international scenarios and to the global university sector. These questions are also original, because they present different points of view coming from different disciplinary sectors: management, organisation, higher education policy, regional policy, sociology of knowledge. In this way, each different aspect of this phenomenon can be analysed and interpreted in a multidisciplinary perspective.

We consider universities as higher education institutions that perform, although in very different degrees, at least three main activities: teaching, research, and services to local and national communities. Our units of analysis are universities and national university systems so that, in such a context, the term 'higher education institution' is used as synonymous with 'university'. 


\section{Changes in Higher Education}

Alison Wolfs statement, 'the belief in education for growth runs deep and wide beyond our political classes, replacing socialism as the great secular faith of our age' (2002, p. 10), is more than a simple provocation. In the West, the belief that knowledge and scientific research are key for individuals' and countries' economic success has caused an increasing attention to formative institutions, and first of all to universities. They are not only authoritative sources but, in many regional contexts, they are the only provider of knowledge. As a result, the number of students enrolled at university has continuously been increasing, from the early 1900s, widely surpassing, in Western Europe, one-third of people interested in the first university [1] enrolment. Almost all European governments have a goal of $50 \%$ of the age cohort that is interested in the first university enrolment in the short term (Organisation for Economic Cooperation and Development [OECD], 2004).

The main changes are as follows:

1. Higher education sector boom regarding total national budgets, university enrolments, graduates, in contrast to decreasing of funding per student (OECD, 2004). Tertiary education quality worsens while, both at local and national level, emphasis on its strategic importance increases.

2. Low rate of return to tertiary education regarding 'comprehensive private internal rate of return to tertiary education'.[2] This indicator is particularly low in Italy [3], giving evidence of the deterioration of financial advantages resulting from higher education (OECD, 2002, p. 126).

\begin{tabular}{ll}
\hline Country & $\%$ \\
\hline United Kingdom & 17.3 \\
USA & 14.9 \\
Denmark & 13.9 \\
France & 12.2 \\
Netherlands & 12 \\
Sweden & 11.4 \\
Italy & 6.5 \\
OECD average & 11.8 \\
\hline
\end{tabular}

Table I. Comprehensive private internal rate of return to tertiary education (source of data: OECD, 2002).

3. High intellectual unemployment. In some regional and national contexts, as in the central Italian one (in accordance with the last available ISTAT [Istituto Nazionale di Statistica] data for geographical area and qualifications), the unemployment rate for people aged 25-34, without schooling, or with just a primary school certificate, is $14.5 \%$ compared with $14.1 \%$ of people having a university degree or doctorate. In all Italian geographical macro areas, the unemployment rate for people having a secondary school certificate is lower than for people with a university degree.

\begin{tabular}{lcccc}
\hline & North-west & North-east & Centre & South \\
\hline Degree and doctorate & 5.6 & 7.9 & 14.1 & 28.0 \\
Secondary school certificate & 3.8 & 3.6 & 9.8 & 27.3 \\
Vocational school & 4.1 & 3.2 & 8.3 & 26.6 \\
Post-primary school & 5.9 & 4.0 & 10.5 & 24.7 \\
Primary or no school at all & 11.1 & 5.8 & 14.5 & 35.6 \\
Total & 5.0 & 4.3 & 10.6 & 26.8 \\
\hline
\end{tabular}

Table II. Unemployment rate, geographical area and qualifications (ISTAT, 2001).

The progressive deterioration in the Italian unemployment and the remunerating situation is highlighted by the last Almalaurea survey (Consorzio Interuniversitario Almalaurea, 2005):

- $54.2 \%$ of graduates are employed one year after they gained their degree (in 2000 the percentage was $57.5 \%$, in $200156.9 \%$ and in $200254.2 \%$ ); $27 \%$ of graduates ( $25 \%$ in 2002 ) retain the job they had before gaining their degree; 
- the percentage of graduates looking for a job rose from $20.1 \%$ in 2001 to $24 \%$ in 2002 and to $25.8 \%$ in 2003 ;

- the unemployment rate for graduates in 2003 (i.e. those who had been looking for a job at least for four weeks before the interview, and were available to work in the next 15 days, in accordance with the ISTAT survey) was $19.2 \%$, and has increased in recent years $(+0.2 \&$ from 1999 to $2000,+1.2 \&$ from 2000 to $2001,+1.5 \%$ from 2001 to $2002,+0.5 \%$ from 2002 to 2003 );

- on a national basis 'the advantage of being graduate is reduced compared with people who have a secondary school certificate; this advantage was equal to $7.4 \%$ in 2002 and it fell to 5.5 in 2003 (Consorzio Interuniversitario Almalaurea, 2005, p. 5);

- three years after graduating, $73 \%$ of people are employed (it was $75 \%$ in 2002 and $77 \%$ in 2001);

- the unemployment rate after three years is $9.2 \%$ (it was $7.9 \%$ in 2002 and $6.2 \%$ in 2001 );

- after one year, graduates' net monthly salary is Euros 969 (-4.5\% compared with 2002, when it was Euros 1.015), after three years it is Euros 1.160, and after five years Euros 1.250: from 2000 to 2002 , the growth rate was $0.1 \%$ compared with $2.5 \%$ in France and $2.3 \%$ in the United Kingdom; Italy was placed twenty-third in the OECD ranking.

Intellectual unemployment and the deterioration of employment opportunities for graduates is, moreover, typical of many European regions (Wolf, 2002).

4. Graduate and postgraduate education boom throughout Europe. There are serious problems in Italy, where the age of graduating is about 28 and where a strong and degenerative positional competition' [4] and 'credentialism' are seriously harmful for social welfare.[5] The lack of availability of suitable professional opportunities after graduating, produced by there being too many graduates to for the market, pushes students to look for further qualifications. They are convinced that this can help them to find better jobs.

5. University offloading by national governments, which tend to delegate financial and coordinative responsibilities regarding universities to regional governments. This happens because of theoretical reasons that consider 'regional innovation systems' and 'regional learning systems' (Cooke \& Morgan 1998) as the best places for developing university policies and for the linkages among universities, firms and institutions. But it happens also because of national government budget problems.

All national governments tend to encourage universities to establish links with the labour market and with local and regional economies. The consequence is an increasing importance of local stakeholders in higher education policies. In weak and particular institutional cases, as the Italian one, they produce a proliferation of branches and new courses with quality assessment problems.

6. New paradigm of knowledge creation. The traditional division of labour between basic research and applied research is more and more harmful in many research fields. According to the new paradigm of knowledge creation, theoretical research and its industrial applications are more and more linked, and need a reciprocal exchange (Gibbons et al, 1994).[6] This means mobility of careers between universities and industries, flexible contracts, industry interest in basic research and publications, greater involvement by universities in getting patents and marketing scientific research; all of this in a context where institutional boundaries are weaker and weaker: 'The boundaries between university and the outside world are porous, and such porosity is sought explicitly'.[7] In this context there is not the traditional university dilemma between internationalism and the need to contribute to local [8] and national economic development because of funds and social preassure: 'The two sides of Strategic Sciences, relevance (local) and excellence (global), can actually be pursued at the same time. Mode 2 of knowledge production, as Gibbons et al (1994), would call it, is finding its institutional forms'.[9]

7. Rising competition among national universities (as a result of their regional pressure to look for funds, students and links with firms and institutions) and among universities of different countries for postgraduate education, using online courses and branches. In European and Far Eastern 
countries, the spreading of online courses and Anglo-American university branches is becoming more and more important (World Bank, 2002).

8. New competitors are entering the higher education market, competing with universities above all in the most liberalised markets. The World Bank (2002) shows a high increase in corporate universities [10] that, in many countries outside Europe, because of the changed paradigm of knowledge production, are now able to issue formal degrees: 'through alliances with existing tertiary education institutions (examples are Bell Atlantic, United Health Care and United Technologies) and because of these alliances in a borderless higher education environment, a few of them have been officially accredited and enjoy the authority to grant formal degrees' (World Bank, 2002, p. 34).

To understand how these deep changes are affecting university governance, it is important to examine the main theoretical models developed in the literature.

\section{Models of Governance in Higher Education}

In management studies, the concept of governance is not clearly defined and even in the Encyclopedia about Corporate Governance we can read that

the concept of corporate governance is poorly defined because it potentially covers a large number of distinct economic phenomenon. As a result different people have come up with different definitions that basically reflect their special interest in the field. It is hard to see that this 'disorder' will be any different in the future.[11]

So, this concept is much more difficult to define when it is extended to more hybrid and complex institutions like universities.

People involved in higher education governance have many different goals. There are external stakeholders: the state and its institutions, the labour and business market, the scientific community, professionals, new generations looking for jobs, families that maintain students, adults who want to get a university degree or update their knowledge; and internal stakeholders: academics and administrative personnel. We can say that university governance refers to all processes and institutions that rule the division and managing of power inside universities and national university systems. Here, power means making decisions that are binding for others.

The first and most famous theoretical model to discuss university governance is undoubtedly Clark's triangle of coordination. It depicts the state authority, the market, and the academic oligarchy as three forces that determine, through their interaction, the way in which a higher education system is coordinated (Figure 1).

Clark's framework has also been employed to explain governance inside the university. It explains both universities' internal forms of coordination, and the relationship between the state and the whole university system. According to Clark, advanced industrial countries have developed different forms of 'coordination' depending on the predominance of the three different components: state, market and academic oligarchy. So, they can be located in this triangle depending on each component's influence: coordination based on market mechanisms (such as in Anglo-Saxon, East European and developing countries), a more state-induced coordination (such as in Sweden and France) and forms of coordination which are based, above all, on the rule of academic oligarchy (such as in Italy and Germany). 


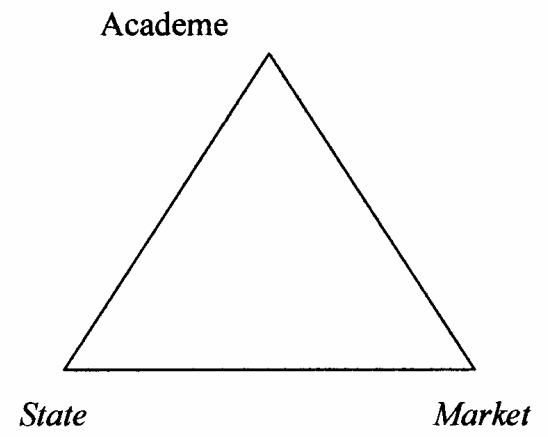

Figure 1. Clark, 1983.

Even examining different country situations in depth, Clark does not provide any clear criteria for classifying countries and locating them inside the triangle. This model has often been criticised because too simplistic and naive. Nonetheless, it is true that Clark's triangle, in spite of many subsequent developments, has been widely adopted to study governance. This happened because of its simplicity and ability to underline the main relevant forces, instead of contingent elements.

Van Vught (1989) tried to simplify this model further, reducing it to two possibilities: state control model and state supervising model. According to Van Vught, the first is typical of the European continental tradition. Here, the state intervenes to regulate access conditions, the curriculum, degree requirements, the examination system, and the appointment and remuneration of academic staff. The academic community retains considerable authority in the regulation of internal university affairs, especially concerning the content of education and research (Van Vught, 1989, p. 331). In this model, authority is shared among academics and the central state, while administrative personnel and internal management are weak and subordinated. The state supervising model, on the other hand, is the one typical of the Anglo-Saxon tradition, in which the weakest authority is that retained by the state bureaucrats and politicians. In this model, power is shared between the academic community and internal management; the state influence is remote and steering at a distance. The state's only task is to supervise the higher education system, in terms of assuring academic quality and maintaining a certain level of accountability. Government does not intrude into the higher education system by means of detailed regulation and tight control (Van Vught, 1989, p. 333).

One of the best known developments of Clark's model is that by Dietmar Braun \& FrancoisXavier Merrien. They use three dimensions to determine the main models of university governance in different national states:

1. substantial control : tight or loose;

2. procedural control: tight or loose;

3. belief system: cultural or service.

- 'State substantial control' is control by the national administration, done by means of financial incentives, goals, ranking system of universities and management by objectives.

- 'State procedural control' is control by the national administration, done by means of detailed regulation of the higher education system and through strict supervision.

- 'Cultural belief system' considers, as its main goal, knowledge conservation and the increasing of knowledge.

- 'Service belief system' considers, as its most important aim, the contribution to the economic and social development of the society and the economy, both national and local.

To compare their model with Clark's, Braun $\&$ Merrien analyse the comparison among countries in 1983 and design the eight combinations that intersect the three variables. Their approach allows us to identify four main governance models, regarding higher education systems, that are essential in order to deal with the research questions we set at the beginning of the article: (1) why and how university governance models are changing; and (2) which new governance models are becoming apparent. 
The four models we describe below are, in fact, useful tools in order to conceptualise the direction, nature and dynamics of change in university governance.

1. Loose substantial and procedural control with a cultural belief system: the 'collegium' governance model. This model is the typical English one of Cambridge and Oxford and of the early universities of Paris and Bologna: free communities of masters and scholars with financial autonomy and independent from the state authority. Politicians take note of them but do not take part in their internal affairs, whose goal is to acquire new knowledge and to hand on existing knowledge from one generation to the next.

In this governance model, decisions are made through a 'dynamic of consent' (Millet, 1962, p. 234), both if these are the result of a discussion, as suggested by Millet (1962) or the sad confrontation of all forces and the predominance of some groups more than others.

The 'collegium' model has disappeared almost everywhere with the birth of national states that fixed rules and procedures to control universities as a consequence of their huge financial aids and their recognition of university degrees as the main way to get into the state bureaucracy. Nowadays, the 'collegial' model still exists in universities able to preserve their independence from the national state, thanks to their financial autonomy and their importance or reputation.

2. Loose substantial control and tight procedural control with a cultural belief system: the 'bureaucraticoligarchic' governance model. The 'bureaucratic-oligarchic' governance model is the typical one of the European continental tradition, above all the Italian and German one. It involves tight procedural control from national governments, and substantial freedom of academic personnel regarding programmes, research and management of universities, with a belief system focused on the cultural role of universities and not actually interested in their service function and relationship with external stakeholders.

Here, government legislation has an important role in managing, in detail, the university internal ruling governance and the whole national system along with formalised 'dynamics of consent'. University leadership is taken by academics, supported by administrative personnel whose main function is to check that universities respect the law. Managerial skills are not a conditio sine qua non to hold the most important offices.

Even if it has been affected by several legislative reforms, this model has not really changed its main rules and has proved to be very resistant to change. That is why it has become more and more unsuitable in the face of the new roles universities are asked to play. The World Bank describes it in this way:

As a form of privatisation of public institutions to the benefit of specific internal stakeholder groups ... The ownership of tertiary institutions has often shifted away from those who should be the main clients (student, employers and society at large) to control by the teaching staff. The raison d'être for some institutions has become to provide staff employment and benefits rather than to serve as educational establishments focused primarily on the needs of the students and the labour market. (World Bank, 2002, p. 62)

This model can, however, allow a more virtuous configuration. This is when loose substantial control and tight procedural control are associated to a service belief system, more than to culture, as in the French case, which can be proud of a long tradition of higher education at the service of the country's labour market and industry. This model is rare because academics, who keep most of the power, tend to emphasise the cultural function of universities more than the service one.

3. Loose substantial and procedural control with a service belief system: the 'market' governance model. In some countries with an Anglo-Saxon culture, the use of the national state legislation to rule universities is quite rare and university institutions are mainly free to manage themselves. This means that the legislation, as it does not provide detailed guidelines, is not so important, while management competences become more important than administrative ones. In such a procedurally and substantially free model, university leaders are asked not only for a knowledge of legislation and administrative practice but also:

- skills to order and use the research to make decisions (benchmarking with other institutions, analysis of the internal organisation, analysis of economic, political and social trends); 
- skills not only to plan, but to develop projects and think creatively;

- skills to coordinate and direct human and technological resources according to university goals and to manage university internal knowledge;

- skills to interact and develop relationships outside universities;

- skills to understand and change organisational procedures and to manage large professional structures;

- skills to work out flexible and efficient procedures requiring few bureaucratic superstructures and able to manage internal activities;

- skills to develop an organisational culture directed to innovation, to risk and to meritocracy;

- skills to motivate human resources.

To avoid degenerative phenomena, the loose substantial control from the national government presupposes university institutions and market mechanisms able to direct the system to social welfare. Among different governance models, this one is, certainly, the model that requires the most developed university institutions and markets.

The 'market' model, typical of the North American tradition, can help to distinguish different models inside the Anglo-Saxon world. As underlined by Neave (2002), in the 'collegial' model typical of the British tradition, that, as the market model, presents a loose procedural and substantial control, the main university stakeholders are internal.

In the British tradition internal stakeholders are those who gained independence from the medieval guilds, thanks to charitable, individual endowments and accumulated resources.[12] In the North American model, characterised by a strong implication of local communities in the creation and financial aid of universities, the main stakeholders are external: the local community and its representatives, the typical board of regents or trustees. That explains the service belief system of North American universities in respect to the cultural belief system of the British tradition.

A university not belonging to the national community is what British and North American institutions have in common, and what distinguishes them from the continental west European tradition: 'The traditional English universities and their counterparts in the United States both subscribed to the principle of ownership of individual institutions rather than to the incorporation of universities into the nation or the national community' (Neave, 2002, p. 98). The AngloAmerican tradition describes universities as 'individual property' and it refers to stakeholders as the founders and owner communities of higher education institutions. The translation of the word stakeholders as 'portatori di interessi' or 'ayant droits' does not show the deep difference between Anglo-American and continental European tradition.

In the west European tradition, on the other hand, the word stake-holding refers to an abstract 'theory of regulated order' which distinguishes traditionally between three spheres of negotiation: (1) the state: parliament, government, Minister of education; (2) academics, students, administrative personnel; (3) external bodies. They are categories with no differences regarding standards of 'property' and their impact on governance. Universities 'belong' to the national state and their being 'individual property' is absolutely inappropriate.[13]

In the North American stake-holding society, the national state is only a primus inter pares. The role of the local community and of external bodies, which have a relationship with universities or whose economic and social wealth depends on them, becomes more and more important.

So, it may happen that continental European and Anglo-Saxon people are using the word 'stakeholders' in higher education issues, thinking they are speaking about the same thing but they are not, since they have fundamentally different views about the concepts of 'community' (national in continental Europe, local in the Anglo-Saxon world) and 'ownership' of universities (obviously and irrelevantly national in continental Europe, of the local and funding community in AngloSaxon countries).

4. Loose procedural control and tight substantial control with a service belief system: the 'new managerialism' governance model. This is the model used in the modern United Kingdom, in the Netherlands and in some non-European countries like Australia and New Zealand. It is the model that should be implemented in those countries, like Italy or Germany, that are looking for a change from the bureaucratic-oligarchic model. 
In the 'new managerialism' governance model universities have a service function, moving away from the classical Weberian scheme of values and rule observance that is always typical of bureaucracy. They adopt a more entrepreneurial spirit and take advantage of the new huge procedural freedom. The national policy maker steers at a distance and supervises the setting of goals, actual results and performance.

This model requires an efficient national bureaucracy, not able to 'hide' behind its own rules, procedures and prohibitions, but able to steer universities by means of policy tools, and fixing goals, incentives and checks. It is a difficult model to implement because it demands a national bureaucratic structure that is able to operate at a distance, and for universities to be able to work with an entrepreneurial spirit in accordance to national guidelines. National bureaucratic structure (that is the Ministry of Education) and universities are asked for elevated management skills and structures that are able to interact well.

In this sense, the ideal mechanism of 'the market' seems easier to adopt, because it does not ask for an efficient national bureaucracy. In many developing countries, the adoption of the market model is, in fact, a useful short-cut taken to overcome a lack of skills of national government coordination.

Anyway, it is necessary to remember that the 'market model' demands an efficient higher education market and for university institutions to be able to work free from substantial and procedural guidelines. These institutions must have more management skills than the ones required by the new managerialism model.

Mechanisms through which the national government controls independent universities can be of different kinds: funds for research and for operational expenses that must respect particular requirements (staff quality and number, student numbers and types, future employment for students, quality and quantities of publications, well-documented social and economic impact of research, each institution's ranking, quality and quantity of teaching programmes); legislation regarding governance; ad hoc funds to encourage the relationship with the labour market and the local community; definition of goals and methods to encourage and test each institution's accountability and National government representatives in government bodies of universities.

This model tries to encourage the concentration of decision-making powers in few bodies: the board of directors, at central level, and the dean in each faculty. In Europe the dean is usually an academic [14] who is appointed by the board of directors, and who manages the whole faculty. With some differences, depending on each university, the dean's functions are:

- strategic management of the faculty, including its institutional structures;

- operational management of the faculty and of support services;

- resource allocation inside the faculty;

- human resource management and its evaluation;

- management of the whole academic activity, including teaching and research.

These four models of governance do not represent all the possibilities to be found in university institutions, but they are certainly the most common configurations [15], both in practice and theory.

\section{Governance Shifts in Higher Education}

In the past, there have been several models of governance in the same institutions. These have had such a great influence that, nowadays, universities seem to be antique archaeological sites with a stratum for each age (Bargh, 1996).

In the deeper stratum, there is the ideal 'collegial' governance model typical of the earliest universities. Above, there is the 'bureaucratic-oligarchic' model with its typical Weberian structures. A bit higher, we can see the influence of the 1960s move towards democratisation: universities as political institutions. In the highest stratum, there is the 'new managerialism' model with concepts and ideas typical of businesses. Sometimes, we can see an additional stratum with the idea of an entrepreneurial university completely focused on innovation and change. What makes universities different from archaeological sites is that, regarding higher education, none of the different epochs seems to be finished. Each one keeps on influencing present universities, making them really complex and remarkable. 
The 'market model' is the fastest spreading model, especially in developing and Eastern European countries, based on a very superficial imitation of the North American model, which is not deeply understood. Private universities grow in countries that encourage university market deregulation, that avoid tight procedural control and are not able to make any effective substantial control.

In developing and ex-communist countries, the number of private higher education institutions can be considered a good example of the market model becoming more widespread. According to the World Bank (2002, p. 70), at the beginning of the 1990s, in Europe and Eastern European countries, there were no private institutions, but since 2002 there were more than 350 . The average proportion of students in private higher education institutions in the Czech Republic, Hungary, Poland and Romania is more than $22 \%$, similar to the United States. In Romania, 54 private higher education institutions, 15 of which are about to receive full accreditation, compete with 57 public higher education institutions. Under Wold Bank pressure and the international cultural climate, Asian, African and South American countries are even more active in the effort to adopt the market model.[16]

West European countries' development seems to be different. Some European countries, with efficient bureaucratic national structures, are moving towards the 'new managerialism model'. Among these are the Netherlands and United Kingdom. The value of the new managerial model is to guarantee the direction and coordination of universities to national states (for example, regarding enrolment taxes, full accreditation, basic requirements for the training national and local offer). This should be done with the definition of aims and aids, and without interfering in the running of the universities: this makes sure that universities have a service function for their external stakeholders.

Taking into account that there have been a lot of changes in higher education (see earlier), the new managerialism model comes from the will (and necessity) of the national state to use universities as policy tools to encourage innovation and linkages between higher education, the labour market and industry. To reach this goal, it is necessary to eliminate tight legislation and substitute, through direct, hierarchical lines, the Weberian 'culture of values' with a 'culture of results'.

Another effect of the new managerial model and of loose procedural control is the shift from ex ante planning to ex post-evaluation, using different evaluation tools, depending on different countries. The new concept of accountability ex post is so widespread, with a great number of indicators, metrics and classifications that Neave (1988) mentions the coming of an 'Evalutative State'.

In spite of attempts of legislative reforms to move towards a new managerialism model, other European countries, like Germany and Italy [17] (Capano 1999), are stuck with the bureaucraticoligarchic' model that, being a 'privatisation' to the benefit of internal stakeholders, is extremely resistant to change. It is, however, completely incompatible with the new demands on universities.

The 'bureaucratic-oligarchic' model of Von Humboldt's (1810) tradition is based, in fact, on four principles, that contrast deeply with the new tendencies:

1. 'Solitude and freedom' of academics. In its rigorous and traditional form, the academic's individual freedom regarding research and programmes, in open and democratic societies that use teamwork, seems to be an obstacle for the internal coordination of research and teaching. In many disciplines, academics are asked to work in groups and to do research which is to the advantage of the department. Consequently, they need to be coordinated. The traditional 'lonely and extravagant thinker' is not compatible with university accountability and its external stakeholders. The autonomy of universities makes sure that no collaboration and no 'work in teamwork' of single academics is directly and negatively reflected on other academics and on the university itself. In order to find additional sources of funds and in order to develop relevant research in a 'Mode 2' society, a lot of contracting with industry is required at the department level: to do that, academics are asked more and more to coordinate with their colleagues and to report on their work.

2. University as a 'national protected space'. The aforementioned process of 'offloading' of universities towards regional and local administrations and other local stakeholders has moved universities away from the state, which had completely financed and protected them. Now, they have to 
operate in an unprotected area. They have to work to find alternative funds, and they are trying to work out relationships with industry and society. In their discussions and in many European universities' planning, academics often refer to 'entrepreneurial universities'. In these universities, being entrepreneurial does not mean to look for profits. It is a continuous inclination to innovation and to change in order to reach their own goals. As well explained by Clark (1998), there are five essential elements to characterise an entrepreneurial university:

- a strengthened steering core able to manage and steer effectively the whole university;

- an expanded developmental periphery made of research centres, societies of consultancy and hybrid academic-commercial institutions, spin-off firms set up by professors and students, agencies for knowledge transfer. All of them must be able to establish useful networks between universities and the labour market;

- a diversified funding base, originated by businesses, local government, foundations, intellectual property royalties, fees from students, services for students, consultancies, alumni legacies [18], making the university not entirely dependent from national government funds;

- a stimulated academic heartland able to produce high quality research and teaching;

- an integrated entrepreneurial culture, made of common values and views regarding the institutional mission, generated and sustained by academic leaders throughout the institution.

- The 'entrepreneurial' approach of each university seems to be more and more necessary, because the public national fund is not able to satisfy the increasing demand for resources, and the university's services are favourable, above all, to individual students and regional and local economies. Both this and the students' increasing requirements for training and jobs that fit their aspirations demands a financial contribution from the people who benefit most from higher education.

3. Cultural orientation of universities. Maintaining, developing and handing down the national culture is just one of the services that universities are asked for, but it is not its main one. Higher education is asked to contribute more and more to the economic development of the countries, regions and places they are placed in and that finance them.

Students enter universities and invest human and financial resources, not only because they love knowledge, but to have the opportunity to find future jobs that can satisfy their professional ambitions, and to repay their families' investments in them. Problems regarding intellectual unemployment, underemployment, employment that does not fit students' specialisations and the decreasing 'comprehensive private internal rate of return from tertiary education' (mentioned earlier) are no longer irrelevant to single universities and to the university national system. They are real problems for university internal stakeholders. That is why they must be checked, analysed and dealt with by universities.

The most successful European universities believe that employment for their graduates must be among their main goals, and they use didactic and placement policies to reach this aim. In many regions, universities are the only knowledge provider, and they are asked to contribute to local economic development with scholars and research compatible with the economy.

The traditional 'cultural belief system' of higher education institutions is not able to provide that.

4. Academics self-government. The traditional self-government of academics was born when universities had a mainly cultural function and little impact on economy. The university's role, increasing in regional and national economic development, has increased the new external stakeholders' role, making their involvement in important decisions necessary.

The complex management of universities asks for managers more than for academics with no management skills. Further, it asks for an administration able to make the university work with fewer legal operational guidelines and a loose procedural control.

Universities' bodies are asked to:

- check threats and opportunities coming from the university itself and from outside (both local and international);

- outline and implement strategies able to create a great number of funds not coming from the national government; 
- fix goals and check their attainment from all the university staff, by means of managerial techniques;

- conciliate contradictions, identify stakeholders and have relationships with them.

In a global higher education scenario, characterised by the 'market model', the future of western European systems will depend on the capacity for reforming the 'bureaucratic-oligarchic model', moving towards that model of coordination of the national university system that we have called the 'new managerialism model'. At the level of each university this model is characterised by strong entrepreneurial features (Clark 1998).

The 'new managerial model' is considered, in fact, a natural development of the European 'bureaucratic-oligarchic' governance, and it is an intermediary solution compared with the much more demanding 'market' model. In the European tradition, in fact, the state has an important role of coordination: this role should be pursued less and less by means of detailed legislation and regulations and should be based on incentives and management by objectives, with an increased university autonomy.

West European countries should pay attention to the Netherlands model because of its cultural and institutional characteristics. From 1970 to 1997, the university central governance in the Netherlands had four main bodies:

1. the university council - composed of 25 members elected by the university community itself: at least one-third academics, no more than one-third non-academic staff, no more than one-third students, sometimes integrated with members of the local community (no more than five); Its functions were: approval of the balance and annual reports, strategic decisions for the university, internal rules and procedures. It included public participation;

2. the executive board - of three members (with the rector), all of them elected by the Minister of Education. Its functions were: to have the powers that were not assigned to the university council, particularly university executive power and implementation policy of the university council. There was no public participation;

3. the board of deans - composed of all deans of departments. Its functions were: consulting regarding teaching and research and giving advice to the Minister of Education regarding election of the rector;

4. the rector - he is the representative of the university and his main function is to coordinate and implement the executive board deliberations.

At the second level of governance there were:

1. the faculty council - no more than 15 members, half of them academics; the others were students and administrative personnel, with the possibility to include, as in the university council, five external members. Their functions were: approval of the balance, election of the dean and of the research committee and education committee members;

2. the faculty board - no more than five members, with all the powers that were not assigned to the faculty council; the distribution of powers was the same as for the executive board and university council;

3. the dean - who coordinated and presided over the faculty council and faculty board functions;

4. the research committee - composed of the great number of academics with advisory powers regarding faculty research programmes;

5. the education committee - half composed by students, with advisory powers regarding programmes and examinations.

At the third level of governance there were disciplinary groups. They were clusters of professors and researchers from the same field, who had to design and implement research programmes according to the faculty guidelines. The chief executive officer of each faculty and the secretary of the university, at central level, were responsible of the university administrative units supervised by the faculty board and the executive board.

In 1997 'Modernisering Universitaire Bestuursorganisatie' (MUB) completely changed the Dutch university governance. The university council, deprived of its main powers, now has advisory and representative functions. The executive board has much more power, and even if it has not been changed, is now completely appointed by the new supervisory board. This is composed of five members, elected by the Minister, who is their only responsible to the Minister. 
The new governance structure favours the Minister's executive powers, making universities freer regarding methods to reach their aims. Even regarding faculties, universities can substitute faculties with deanships. The dean is chosen by the executive board among internal and external members, introducing a strong monocratic power in the university. Consequently, there has been a transfer from collegial to individual responsibility. The executive board refers to the dean and no longer to the faculty. In their turn, the dean refers to each academic and no longer to the faculty council. The disciplinary research groups, typical of the collegial tradition, have been replaced by 'research directors', creating a vulnus (wound) in the self-rule Humboldtian tradition.

The dean has the following powers:

- to choose the governance model of the faculty and staff;

- to design and organise faculty research and teaching programmes;

- to cooperate with the executive board to work out a budget and a strategic plan;

- to work out, supervise and evaluate examination procedures;

- to choose the faculty staff;

- to design general research lines;

- to work out the faculty research programmes for the year [19]

- to choose directors for each teaching programme.

We can, therefore, say that the dean is completely responsible for the faculty management. Strategic planning, the operational planning, management of human resources, teaching and research are his responsibility. Thinking that deanship is only a managerial function is wrong.[20] In the Netherlands, it has, in fact, a role of mediation regarding managerial demands on the central administration and the academic life of the faculty: 'the deanship is a schizoid position. From the faculty's perspective the Dean is working with the forces of Mordor; but at the same time he is expected to be the protector of the Shire' (De Boer et al, 2005, p. 54).

We may so conclude that it was a governance reform that increased both substantial control by the national government and procedural freedom at the university level.[21].

The case of Dutch universities is, in a way, emblematic because of their ability to conciliate knowledge and local economic development with substantial control by the national government but remain free enough to qualify some of them as 'entrepreneurial universities' (Clark, 1998). Some interviews by the academic staff of University of Twente, one of the 13 Dutch public universities, may well give a flavour of what is going on:

We are already considered the most entrepreneurial university in the Netherlands ... We have to find money from the market. We do it well both in social sciences and in engineering. There is a lot of contract research and setting up of companies. There is even the idea of making students become young entrepreneurs as well.[22]

The University of Twente, which receives more than one-third of its funds from contracts with private companies, believes, in fact, that one of its main goals is the employment of its own students (as employees or working on their own). The 'temporary entrepreneurial programme' is a successful programme that gives students and professors funds and office space inside the faculty and the campus. Thanks to this programme, the University of Twente has created many new knowledge-based businesses that have a strong research relationship and collaboration with the university itself. These spin-off companies have showed good potential to survive and grow.[23] Contracts with industry have been considered as opportunities to satisfy the classical students' wish of studying 'real' matters and they are a source of financial freedom and independence from the national government: 'the advantage is gaining greater academic freedom. If we can get funds outside of government funding, it gives us more financial autonomy'.[24]

The example of the University of Twente also proves that there is no real excuse for social sciences departments not raising extra financial resources.[25] The University of Twente and other cases we investigated [26] demonstrate that in post-industrial and service-oriented societies, if good social science is provided, social science departments can be even more effective than natural science departments in raising financial resources.

In the Dutch case (de Boere et al, 1998) the MUB legislation has not produced big changes in the university governance as most of these changes were already operational. It may well be suggested, in fact, as de Boere did (1998), that emerging practices demanded a formal legislation to 
regulate them more than the other way round. According to Gornitzka, A. \& Maassen, P. (2000), the real change regarded culture and happened in the early 1990s. It was characterised by the introduction of a different language in government and university documents. Students became 'clients' and 'consumers'. Knowledge became a 'product', and administrators became 'managers' of universities working in the education and research 'market'. The logical order of things does not matter; we are interested to underline the university's ability to adjust to changes and develop culturally and organisationally, leaving aside governance models already formally in place.

We can get two results: firstly, the legislation inability to stop changes in universities; and secondly scepticism about the effectiveness of reforms entirely based on new legislation.

Before the MUB Act, in a comparative study between Germany and the Netherlands, Maassen \& Van Vught (1994) mark two main models of governance - the state control model and the state supervising model. They consider these two countries as respective representatives of each model and work out two hypotheses: (1) the more a governmental steering model has the characteristics of the state supervising model (and the less it has the characteristics of the state control model), the higher the level of innovativeness of the higher education institutions that are confronted with that steering model; and (2) the more a governmental steering model has the characteristics of the state supervising model (and the less it has the characteristic of the state control model), the higher the level of flexibility of the higher education institutions that are confronted with that steering model.

Considering Germany and the Netherlands as paradigmatic examples of the state control model and the state supervising model, respectively, transforming concepts of 'innovation' and 'flexibility' into 'ability to implement and design new curricula' and 'ability to find new financial means in a context of decreasing state funding', Maassen \& Van Vught (1994) show that both hypotheses are verified. They say that the Dutch model is much more innovative and flexible than the German one.

Germany is the homeland of Von Humboldt's concept of 'solitude and freedom' in a context with a tight procedural control by the state and substantial freedom for academics. The Netherlands are, on the other hand, one of the countries that better adopted the new managerial model. The comparison with these two countries is, then, particularly important.

Gornitzka \& Maassen's analysis (2000) describes the German higher education system as a complex 'pluralist-corporative' organisation. Here, the university role shows the result of a difficult mediation among all the interests voiced by different groups. These groups are: trade unions, professional associations, regional and federal authorities and even the Minister of Education. In this system, policy decisions are not made by the government or by the main members of the university. They come from corporate networks that are changeable and segmented. The same government power decides about its own steering role in association with clusters of interests: 'the autonomy of universities and colleges is negotiated and the result of a distribution of interests and power. Change of higher education depends on changes in power interest and alliances' (Gornitzka \& Maassen, 2000, p. 271).

In really provocative statement, Dieter Simon, ex-president of Wissenschaftsrat (the German science council) has described German universities as 'Im Kern verrottet' or 'rotten to the core' (Stucke, 1999, p. 165). This statement has become a slogan to show public dissatisfaction towards those universities. Almost everyone knows the main cause of such dissatisfaction:

\footnotetext{
With their institutionally granted academic freedom of teaching and research professors are similar to small businessmen with a number of subordinates. But as civil servants, professors also enjoy the respective rights, especially the right that they cannot be dismissed. Thus to put it in a nutshell, professors are small businessmen who cannot go bankrupt - which is an important restriction to all kind of competitive pressure ... It is no wonder, then, that academic selfregulation among professors shows a marked tendency to preserve the organisational status quo. (Schimank et al, 1999, pp. 185-186)
}

The legislator has tried to free German universities from their academic oligarchy, making leadership's role more 'professional': for example prolonging rectors' and deans' time in office and giving them new responsibilities. It has been a timid way to introduce some early forms of management, but it has not been successful because rectors and deans have not been given more 
power but only new responsibility, and academics increasingly involved in management have not been granted diversified career opportunities.

In Germany there has also been a debate regarding the opportunity to create university boards (Hochschulrate). Their tasks should be: supervision and evaluation of university performance, establishment and removal of professorships, recruitment of professors and researchers, and the establishment and closing of departments. The idea to introduce to university boards non-academic personnel as representatives of economy and society, to make universities have a service role and develop a relationship with external stakeholders has been deeply examined (Stucke, 1999).

Geuters \& Maassen (1996) made an empirical analysis comparing decisional processes in universities, in four different countries (Germany, the Netherlands, Sweden and England). They asked academics to evaluate, using a scale of one to five: their being involved in administrative activities; power distribution between faculties and universities' central bodies; and their influence on academic policy, courses and research projects. Subjectivity of evaluation, in very different country systems, has not been able to produce scientifically acceptable answers regarding single national differences. However, it has been possible to obtain some general conclusions:

1. context, cultural and national circumstances have a great impact, which is statistically significant, on what academics think about university governance;

2. nationality influences opinions more than disciplinary background and the kind of institution (college, university, others) and, in many cases, more than employment status;

3. in all the countries, academics feel that administrators do not provide competent leadership;

4. despite the long time spent on administration, academics believe their influence on policy making to be marginal;

5. in all these countries you can feel a kind of dissatisfaction and a wish for a deep governance change.

De Boer et al (1996) made a similar analysis based on 376 questionnaires sent to rectors and vicechancellors of six different country universities (Sweden, Denmark, Germany, France, United Kingdom and the Netherlands). It showed that academics, central administrators and a few other members of central bodies are deeply involved in decision making, while staff and administrators who are not part of central bodies have a marginal role. Sweden, Denmark and France obtain average results but each of them shows a difference: in Sweden, there is a low participation of central councils; in France, there is a higher participation of administrative personnel; in Denmark a high participation of decentralised councils. The Netherlands, United Kingdom and Germany are much more different. In the Netherlands, the decentralised councils' role is strong and a decentralised governance model prevails. In the United Kingdom, central administrators' power is strong and a centralised university governance prevails. In Germany, collegial decision making, controlled by academics, prevails:

Denmark, Sweden and the Netherlands appear to feature rather decentralized institutions.

Germany shows signs of domination by academics, in particular through its council structures.

France seems hard to typify .. while the United Kingdom ... has a very distinctive combination of

academics and central administrators as the most active players. (De Boer et al, 1996, p. 105)

The authors' conclusion is that: (1) Sweden, Denmark and France's collocation is intermediate; (2) Germany is characterised by negotiation, collective responsibility, conflicts, consultation, decentralisation, informality of real decision making, power dispersion, almost absence of topdown decisional mechanisms; (3) the United Kingdom is characterised by low-level consultation, top-down decisional mechanisms, consensus and rivalry; (4) the Netherlands show their democratic governance structure with a great participation of interested groups, but with low collective responsibility and hierarchical informality of decisional processes.

These researches demonstrate that the European scenario is various, complex and deeply nationally based. It is characterised by single national features and, above all, it is looking for a more effective governance models. The above analysis underlines the difficulty of cross-national comparative studies to show national differences among single institutional aspects and to put national states into predefined conceptual schemes that would overlook their historical, normative and cultural characteristics. 
Because of their being abstract, Braun \& Merrien's governance models (1999), they are the most useful tools in order to understand the causes of change and the direction of change.

To preserve legitimacy, each higher education system in Western Europe is moving along its own institutional paths, respecting its history and tradition. But anywhere, it is possible to find a tendency for the 'new managerialism' model, because universities have realised that the 'bureaucratic-oligarchic' model is not able to face new challenges. Their fear is that, after a long time, the use of language and tools typical of businesses, in order to gain legitimacy [27],could produce such deep changes that it would affect those traditional characteristics that made them legitimate and authoritative in the first place.

In that sense, the main problems that scholars are interested in are: restriction on knowledge circulation in the academic world and delay in the publication of researches that could have a high economic impact (above all in pharmacology, biotechnology and engineering); achievement of patents by universities on basic research results, that could be harmful for scientific progress (above all regarding biotechnology); compromise on standards and on ethics, in order to favour outside relationships (for example, in consulting activity and in the number of students or graduates each year). Many international experiences [28] show, however, the impossibility of the status quo and the possibility of change preserving legitimacy. European universities are facing changes in different ways. Some of them go on respecting their century-old tradition, almost without any changes. Others have gone for 'full-blooded entrepreneurial approaches' (McNay, 1999, p. 58). Some other universities are trying to solve their problems using a culture of control and cost savings. In this move from old to new governance models, the result is an increasing level of uncertainty regarding the internal organisation and the resistance to this change. Trying to be conservative, on the other hand, means to be condemned to irrelevance and marginality to the advantage of other university national systems.

This risk is particularly high in national systems with long traditions and in the transition from the 'bureaucratic-oligarchic' to the 'new managerial' model. In these nations, a long and respected historical tradition, that proved universities to be able to survive through deep social and economic change, may indeed be an obstacle to any transformation agenda. We can add the traditional fear to look for new solutions and to lose rights and privileges during the change process.

This situation explains the sometimes ambivalent and weak attitude of the German academic body regarding those universities' increasing autonomy. According to Weiler (2005), in fact, German academics prefer the important but less operative authority of the state than 'the rather close and possibly quite enterprising authority of a university president or dean to whom the state has delegated a considerable decision-making authority' (Weiler, 2005, p. 183). Though Weiler's point of view may not be widely shared and German universities' governance is indeed under a process of reform [29], it is a fact that the 'bureaucratic-oligarchic' model is strongly resistant to change in Germany, Italy [30] and other European countries.

A detailed study of history of universities will show, however, that in order to survive, higher education systems have radically changed their governance over the centuries.[31] In the Middle Ages, the 'collegial' model of the free universities of Bologna and Paris moved towards national states. From these, they obtained funds, protection and, above all, full accreditation of degrees, that was so important in XIX century to get into the state bureaucracy that was the only real employment for graduates. On the other hand, these universities were no longer as free as they used to be.

It is time now to realise the necessity to introduce in university government bodies, professionals with management and entrepreneurial skills able to make these complex institutions work in a context of procedural freedom and autonomy. The other important goal to reach is to accept and work out the substantial steering role of the national state and to respond to external stakeholders' demands.[32] It will not be difficult, if we compare such a change with the governance change we had in the transition from the 'collegial' model of medieval tradition to the 'bureaucratic-oligarchic' model of the continental European national state. Universities will greatly benefit from this change, in terms of legitimacy, relevance, effectiveness and efficiency.

The progressive international liberalisation of higher education markets (see the best postuniversity education; Anglo-Saxon universities are more and more dominant in it) does not ask for weak reforms and substantial immobility. Thanks to the power they properly have and 
decisiveness they are asked for, continental European national states seem to be the only possible source of change and authority, in order to overcome a dangerous resistance and introduce necessary reforms in university governance. They should act with no further delay 'before the emerging culture of cynicism, verging on contempt becomes dominant and destructive' (McNay, 1999, p. 58).

\section{Notes}

[1] In 2002 the USA, followed by Japan, were top of the classification with two-thirds of students entering tertiary education (Wolf, 2002, p. 173).

[2] The rate of return represents a measure of returns obtained, over time, relative to the cost of the initial investment in education (the costs equal tuition fees, forgone earnings net of taxes adjusted for the probability of being in employment less the resources made available to students in the form of grants and loans; benefits are the gain in post-tax earnings adjusted for higher employment probability less the repayment, if any, of public support during the period of study) (OECD, 2002).

[3] Italy is taken as a good and significant example of the shortcomings of the traditional Von Humboldt model we are going to analyse and criticise in the following paragraphs. The preference we give to the Italian case is justified by both its criticality and our obvious access advantages and privileged point of view.

[4] For a definition and analysis of 'positional competition' and 'credentialism' in higher education, see Tavoletti (2004b). Positional competition in higher education is the 'social fight' to obtain places in elite schools and the professional faculties of leading universities. The problem about 'positional goods', in education as elsewhere, is that they are hierarchical in character (by definition some are more valuable than others) and not just 'scarce', like all economic commodities, but scarce in absolute terms, in the sense that total supply is fixed. Positions of social leadership are finite and cannot be expanded through changes in education; and there cannot be universal or equal access to such positions, except when education has no positional value. So that when the number of educated people with a given level of credentials increases, the value of these credentials must decline and people look for more credentials and credentialism is in action. Education may provide knowledge, skills and social experiences without limitations, but as long as it is employed as a screening device for social positions 'advance for everyone' is an illusion: 'At any moment in time, and for any one person, standing on tiptoe gives a better view, or at least prevents a worse one. Equally, getting ahead of the crowd is an effective and feasible means of improving one's welfare, a means available to any one individual. It yields a benefit, in this sense, and the measure of the benefit is what individuals pay to secure it. The individual benefit from the isolated action is clear-cut. The sum of the benefits of all the actions taken together is nonetheless zero.' (Hirsch 1976, p. 7).

[5] For new graduates with a result of $105 / 110$ and, above all, for those with first class honours, employment gets minimum values. The success they got at university makes these students have ambitious expectations. ... To keep on with studies are, above all, young people (!) coming from high social and cultural families and those who have had the best performances. ... These values are rising compared with the ones of the previous survey (total $+4 \%$ that, in some cases reaches $+7 \%$ )... This situation shows a problematic higher education system that becomes even more difficult when we realise that the average age of Italian students to gain a first university degree is about 28' (Consorzio Interuniversitario Almalaurea, 2005).

[6] International literature refers to Gibbons's new paradigm of knowledge production (Gibbons e al, 1994) in accordance with his Mode 2 neologism. This contrasts with the traditional Mode 1 as: (a) traditional division between basic and applied research; (b) linear move from theoretical research knowledge to applied industrial research; (c) strong division among disciplinary sectors, university and the labour market.

[7] Rip, 2002a, p. 6.

[8] Universities are by tradition - one might say by intellectual necessity - open to participation by scholars all over the world. Yet their sources of funding are almost entirely domestic, and in most countries (including the United States) primarily governmental. Politicians may be expected to ensure that the benefits of university research are effectively, if not primarily, captured by domestic workers and investors' (Branscomb, 1999, p. 3). 
[9] Rip, 2002b, n. 27, p. 128.

[10] World Bank (2002, p. 34) recorded 1600 in 2002 and 40010 years earlier.

[11] The Encyclopedia about Corporate Governance (1999, p. 1).

[12] That medieval process of progressive independence is indeed typical of other European countries but Britain seems to be the only one in which universities preserved some independence after the establishment of the national state and where not fully 'incorporated' by the national public sector; that makes them much more similar to North American universities.

[13] Continental European tradition, just like the Anglo-Saxon world, is far from being a block, but all the European Continental nations have in common the idea that 'individual property' is a concept inappropriate to universities, just like the Anglo-Saxon traditions have in common the opposite idea, both linguistic and substantial, of individual 'stakeholders' and ownership, either internal (British tradition) or external (North American tradition).

[14] A recent survey by De Boer et al (2005), shows, on the other hand, a much more managerial background in the United States and Australia.

[15] The other two governance models are the 'bureaucratic-etatist' and the 'corporatist-statist'. The 'bureaucratic-etatist' governance model shows a tight substantial and procedural control with a cultural belief system. In this model the state sees universities as institutions with a cultural and knowledge mission and becomes involved in their management to reach this goal. It is a model that is difficult to find in reality, because, when states have a strong substantial and procedural control, they try to direct universities to have a social, political and economic mission. It is, moreover, a 'possible' model, that presupposes a state both centralised and favoured to interferences and respectful of universities' 'cultural' mission.

The 'corporatist-statist' model underlines, on the other hand, a tight substantial and procedural control by the state, with a service belief system. It is the typical model of authoritarian and centralised countries with a strong control over universities favouring politics and its national interests. North Korea is the paradigmatic example of this model.

[16] In Sub-Saharan Africa, from 1990 to 1999, the number of private higher education institutions increased from 30 to 85 (World Bank, 2002, p. 69): Kenya, 21; Tanzania, 14; Ghana,12; Uganda,11; Sudan, 8; Democratic Republic of Congo,6; Mozambique, 5.

[17] In the last 15 years, legislative growth has not shown a real development in the Italian governance system but it has, on the contrary, highlighted the inability to modify the 'bureaucratic-oligarchic' model just through legislation. See Capano (1999) for a history of unsuccessful legislative reforms.

[18] No case shows better the difference between the North American - 'community based' - and the continental European - 'national based' - model as legacies from ex-students: financially important in the first case, almost absent in the second one. American people are really grateful to their universities and want to contribute so that universities can keep on working well for future generations. The Europeans believe that higher education is a right, which should be provided by the national state.

[19] In many European countries, the research programme is designed by departments and not by faculties.

[20] The Netherlands has adopted a somewhat softer version than Anglo-Saxon countries and has done so more recently (De Boer, 2003).

[21] After the MUB Act (1997), the direction of change has remained basically unchanged. In the latest Higher Education and Research Plan (2004), Dutch Ministry of Education, Research and Culture, there is even the idea to sign performance contracts between the Ministry and each higher education institution as the ultimate and almost 'private' expression of tight substantial control and complete procedural freedom. See Huisman, forthcoming 2006; Porto \& Weert, 2005.

[22] Currie, et al, 2003, p. 64.

[23] For details and data about the 'temporary entrepreneurial programme', see Lazzeretti \& Tavoletti, 2005.

[24] Ibid.

[25] See Lazzeretti \& Tavoletti (2005) for data about university-industry linkages and social sciences department fund raising at the Universisty of Twente. 
[26] See Tavoletti (2005) for another case study of social science departments successful in establishing profitable linkages.

[27] For a European picture of changing styles of governance under the flag of 'managerialism', see Van Kersbergen \& Van Waarden (2004).

[28] We made a special reference to the University of Twente because it is a deeply studied peripheral institution, without any remarkable competitive advantage. In that sense it can be a good case to imitate for the numerous small and medium European universities that are the real backbone of the European national higher education systems. In our view, the so often quoted cases of high flying and highly endowed institutions, such as Cambridge and Oxford, whose success is based on unique circumstances, could be a harmful model to imitate for 'ordinary' universities.

[29] In 2004 Länder governments have launched proposals for new higher education laws (e.g. BadenWurttemberg and Northrhine-Westphalia) which mainly aim to strengthen the autonomy of the universities. See Centre for Higher Education Policy Studies (2005) for a review of the reform process, with specific reference to (a) political debates around the distribution of policy competences between federal and Länder governments; (b) staff structure and introduction of the junior professor.

[30] See Capano (1999) for a detailed investigation of the resistance to change of the Italian 'bureaucraticoligarchic' model.

[31] For a short but effective historical excursus of universities see Perkin (1991).

[32] Other European countries' experiences should make academics think about the economic and social consequences of resisting national reforms: 'the populist anti-intellectual base of the Thatcher government denigrated the authority of intellectuals in a fashion somewhat akin to the bullying of clever children at school. Teachers were blamed for the failings in society. Universities were blamed by employers for the lack of graduate skills. ... the voice of the academic oligarchy in the national level has been ignored, that of academics within institutions has been muted' (McNay, 1999, p. 41).

\section{References}

Bargh, C., Scott, P. \& Smith, D. (1996) Governing Universities, p. 15. Buckingham: Society for Research in Higher Education and Open University Press). Branscomb L.M. (1999) Industrializing Knowledge: university-industry linkages in Japan and the United States. Boston: MIT Press.

Braun, D. \& Merrien, F. (Eds) (1999) Towards a New Model of Governance for Universities? A Comparative View. London: Jessica Kingsley.

Capano G. (1999) Italy: the endless transition, in D. Braun \& F. Merrien (Eds) Towards a New Model of Governance for Universities? A Comparative View. London: Jessica Kingsley.

Centre for Higher Education Policy Studies (2005) Issues in Higher Education Policy: an update on higher education policy issues in 2004 in 11 Western countries, International Higher Education Monitor, March, Enschede, Netherlands.

Clark B.R. (1983) The Higher Education System: academic organisation in cross national perspective. Berkeley: University of California Press.

Clark B.R. (1998) Creating Entrepreneurial Universities: organizational pathways of transformation. Oxford: Pergamon.

Consorzio Interuniversitario Almalaurea (2005) Condizione occupazionale dei laureati, indagine 2004. http:/ / www.almalaurea.it/

Cooke P. \& Morgan, K. (1998) The Associational Economy. Oxford: Oxford University Press.

Currie J., De Angelis, R., De Boer, H., Huisman, J. \& Lacotte, C. (2003) Globalizing Practices and University Responses. Westport: Praeger.

De Boer H. (2003) Who is Afraid of Red, Yellow and Blue? The Colourful World of Management Reforms, in A. Amaral, V. Meek \& I. Larsen (Eds) The Higher Education Managerial Revolution? vol. 3, pp. 89-108. Dordrecht: Kluwer.

De Boer H., Denters, B. \& Goedegebuure, L. (1998) On Boards and Councils: shaky balances considered. The Governance of Dutch Universities, Higher Education Policy, 11(2/3), pp. 103-110.

De Boer, H., Goedegebuure, L. \& Meek, L. (2005) New Public Management - new styles of management? From General Ideology to the Realities of Being a Dean in Universities. Paper presented at the Oslo Summer School 2005. 
De Boer H., Goedegebuure, L. \& Van Vught, F. (1996) Governance and Management of Higher Education Institutions: a comparative analysis of institutional decision-making processes in five western european countries; in P. Maassen (Ed.) Inside Academia: new challenges for the academic profession. Utrecht: De Tijdstroom.

Encyclopedia about Corporate Governance (1999) http:/ / www.encycogov.com/WhatisGorpGov.asp (accessed 24 June 2005).

Geuters P. \& Maassen, P. (1996) Academics and Institutional Governance: an international comparative analysis of governance issues in Germany, the Netherlands, Sweden and the United Kingdom, in P. Maasen (Ed.) Inside Academia: new challenges for the academic profession. Utrecht: De Tijdstroom.

Gibbons M., Limoges, C., Nowotny, H.,Schwartzman, S.,Scott, P. \& Trow, M. (1994) The New Production of Knowledge: the dynamics of science and research in contemporary societies. London: Sage.

Gornitzka, A. \& Maassen, P. (2000) Hybrid Steering Approaches with Respect to European Higher Education, Higher Education Policy, 13, pp. 267-285.

Hirsch, F. (1976) Social Limits to Growht (New York: Twentieth Century Fund)

Huisman., J. (2005) Shifting Boundaries in Higher Education: Dutch hogescholen on the move, in A. Amaral et al (Eds) Non-university Higher Education, a comparative perspective, forthcoming 2006.

Istat (2001) Unemployment rate in 2001. http: / / www.istat.it

Lazzeretti, L. \& Tavoletti, E. (2005) Higher Education Excellence and Local Economic Development: the case of the Entrepreneurial University of Twente, European Planning Studies, 13(3), pp. 475-493. http: / / dx.doi.org/10.1080/09654310500089779

Maassen, P. \& Van Vught, F.A. (1994) Alternative Models of Governmental Steering in Higher Education. an Analysis of Steering Models and Policy-instruments in Five Countries, in L Goedegebuure \& F.A. Van Vught (Eds) Comparative Policy Studies in Higher Education. Oslo: Lemma.

McNay I. (1999) Governance of Universities and Modernisation of the State, in D. Braun \& F. Merrien (Eds) Towards a New Model of Governance for Universities? A Comparative View. London: Jessica Kingsley.

Millet J. (1962) The Academic Community. New York: McGraw-Hill.

Neave, G. (1988) On the Cultivation of Quality, Efficiency and Enterprise: an overview of recent trends in higher education in Western Europe, 1986-1988, European Journal of Education, 23, pp. 7-23.

Neave G. (2002) The Stakeholder Perspective Historically Explored, in J. Enders \& F. Oliver (2002) Higher Education in a Globalizing World: international trends and mutual observations. Dordrecht: Kluwer.

Organisation for Economic Cooperation and Development (OECD) (2002) Education at a Glance: OECD indicators. Paris: OECD.

Organisation for Economic Cooperation and Development (OECD) (2004) Education at a Glance: OECD indicators. Paris: OECD.

Perkin H. (1991) History of Universities, in P. Altbach (1991) International Higher Education. Boston: Garland.

Rip A. (2002a) Strategic Research, Post Modern Universities and Research Training. Paper presented at the International Conference on Science, Training and Career: changing modes of knowledge production and labour markets, University of Twente, 21-22 October 2002.

Rip A. (2002b) Regional Innovation Systems and the Advent of Strategic Science, Journal of Technology Transfer, 27, pp. 123-131. http:/ / dx.doi.org/10.1023/ A:1013108906611

Schimank U., Kehm, B. \& Enders, J. (1999) Institutional Mechanisms of Problem Processing of the German University System - status quo and new developments, in D. Braun \& F. Merrien (Eds) Towards a New Model of Governance for Universities? A Comparative View. London: Jessica Kingsley.

Stucke A. (1999) Higher education policy in Germany: is there any strategy? in D. Braun \& F. Merrien (1999) Towards a New Model of Governance for Universities? A Comparative View. London: Jessica Kingsley.

Tavoletti E. (2004) Higher Education and High Intellectual Unemployment: does education matter? An Interpretation and Some Critical Perspectives, in P. Cooke \& A. Piccaluga (Eds) Regional Economies as Knowledge Laboratories. Northampton: Edward Elgar.

Tavoletti E. (2005) The Local and Regional Economic Role of Universities: the case of the University of Cardiff. Paper presented at the Triple Helix International Conference, Torino, May 2005.

Van Kersbergen, K. \& Van Waarden, F. (2004) Governance as a Bridge between Disciplines: crossdisciplinary inspiration regarding shifts in governance and problems of governability, accountability and legitimacy, European Journal of Political Research, 43, pp. 143-171.

http:/ / dx.doi.org/10.1111/j.1475-6765.2004.00149.x 
Van Vught, F.A. (1989) Governmental Strategies and Innovation in Higher Education, London. Jessica Kingsley. Von Humboldt W. (1970) Università e umanità, Naples: Giunta Editori (first published 1810).

Weert, E. de (2005) The Netherlands, in J.J.F. Forest \& P.G. Altbach (Eds) International Handbook of Higher Education. Dordrecht: Kluwer.

Weiler H. (2005) Ambivalence and the Politics of Knowledge: the struggle for change in German higher education, Higher Education, 49, pp. 177-195. http: / / dx.doi.org/10.1007/s10734-004-2921-7

Wolf A. (2002) Does Education Matter? Myths about Education and Economic Growth. London, Penguin.

World Bank (2002) Constructing Knowledge Societies: new challenges for tertiary education. Washington DC: World Bank.

ERNESTO TAVOLETTI has taken a PhD in Economics and Management of Firms and Local Systems at the University of Florence, and is now a research fellow at the University of Macerata. Correspondence: Ernesto Tavoletti, Department of Studies on Economic Development, University of Macerata, p.zza Oberdan 3, Macerata, I-62100, Italy (ernesto.tavoletti@unimc.it).

LUCIANA LAZZERETTI is a Full Professor of Management at the University of Florence, Department of Management. She has been coordinating for four years the doctoral programme in Economics and Management of Enterprises and Local Systems. She writes extensively about cultural districts, art cities and higher education. Correspondence: Luciana Lazzeretti, Università degli Studi di Firenze, Dipartimento di Scienze Aziendali, via delle Pandette 9, I-50127 Firenze, Italy (luciana.lazzeretti@unifi.it). 